Article

\title{
Navigating Transitions for Sustainable Infrastructures-The Case of a New High-Speed Railway Station in Jingmen, China
}

\author{
Xinyu Liu ${ }^{1, *}$, Daan Schraven ${ }^{1}$, Mark de Bruijne ${ }^{2}$, Martin de Jong ${ }^{3,4}$ and Marcel Hertogh ${ }^{1}$ \\ 1 Faculty of Civil Engineering and Geosciences, Delft University of Technology, Stevinweg 1, \\ 2628 CN Delft, The Netherlands \\ 2 Faculty of Technology, Policy and Management, Delft University of Technology, Jaffalaan 5, \\ 2600 GA Delft, The Netherlands \\ 3 Rotterdam School of Management, Erasmus University Rotterdam, Postbus 1738, \\ 3000 DR Rotterdam, The Netherlands \\ 4 School of International Relations and Public Affairs, Fudan University, 220 Handan Road, \\ Shanghai 200433, China \\ * Correspondence: x.liu-9@tudelft.nl
}

Received: 29 June 2019; Accepted: 1 August 2019; Published: 3 August 2019

check for updates

\begin{abstract}
Sustainable development and Circular Economy (CE) have drawn massive attention worldwide. Construction practices consume large amounts of materials, resources and energy. Sustainability and CE could play a big role in reduction efforts. However, the potential influence of both concepts on the planning and construction of large infrastructures remains unexplored. This paper investigates how professionals involved in a high-speed railway station project in the Chinese city of Jingmen envision the use of sustainability and CE for the planning and construction of the railway station and its surrounding areas. We reviewed policy documents and interviewed local professionals with the Triple Bottom Line (TBL) framework. The analysis reveals opportunities for improvement towards sustainability and the interdependence between the dimensions in the TBL framework for the railway station and its surroundings. The case shows that local professionals identify ample opportunities for improvement (presented as "sustainability ideas"), but none appear truly sustainable. These insights provide evidence that the hierarchical introduction of transition(s) creates a cognitive silo for local professionals when envisioning sustainability ideas. In the TBL framework, this study finds a useful and novel approach to break down the silos, because the TBL stresses the interdependence between the various sustainability dimensions.
\end{abstract}

Keywords: sustainability; Circular Economy (CE); Triple Bottom Line (TBL); transport infrastructure; railway station; Jingmen; China

\section{Introduction}

Increasing demand on infrastructures in terms of energy consumption, raw material demand, and greenhouse gas emissions pose a serious threat to sustainability [1]. This demand in itself has spurred infrastructure construction. In China alone, the construction works contribute to one-third of pollution such as construction waste [2]. With respect to material use, on the one hand, construction works are known to require large amounts of new materials, whereas, on the other hand, they generate large amounts of waste, resulting in such a negative environmental impact $[3,4]$. In China, construction waste totals well over 100 million tons per year, roughly $45 \%$ of overall societal waste [2]. Furthermore, nearly half of the national $\mathrm{CO}_{2}$ emissions can be attributed to infrastructures [5]. 
To address these challenges, new sustainability solutions for infrastructure construction need to recognize the interdependence of the benefits gained and the impact of new solutions across multiple dimensions of sustainability. For example, the re-use of second-hand construction materials for new construction actually provides economic benefits, because it typically requires less monetary input compared with new construction materials. From the environmental side, re-use means, for example, less need for the production of new materials or saving $\mathrm{CO}_{2}$ emissions. These benefits show that ideas to increase sustainability can have interdependent effects across multiple dimensions. Recent reports on sustainability transitions are becoming increasingly aware of the importance of these interdependencies in global developments [6] like Circular Economy (CE) [7], which adheres to both economic and environmental aspects of sustainability [8]. The multidimensional character of the concept of sustainability in a multitude of transitions can create barriers to sustainability, and how to deal with them currently remains unresolved in literature on implementing sustainability $[9,10]$.

To gain more insight into the issues surrounding the multidimensional character of sustainability in a multitude of transitions, this article focuses on an infrastructure project at the local level of a city in China, more specifically on a transport infrastructure project. On the one hand, the local public professionals need to address a multitude of transition requirements in infrastructure design. Specifically, they are simultaneously exposed to multiple programs and laws when planning and constructing new infrastructures. However, to what extent these are aligned remains unclear. For example, Chinese cities are faced with different national programs and laws, like the National CE Promotion Law $(2008,2018)$, the 13th Five-Year Eco-Environment Protection Planning (2016) and the Mid- and Long-Term Railway Network Planning (2016). As a consequence, resources could be lacking, or dilemmas can arise during these projects as a result of different or even conflicting requirements. On the other hand, planning officials are also offered the opportunity to incorporate multiple sustainability ideas in these infrastructure designs potentially upping the impact. In essence, this leaves the question, "how do local professionals envision sustainability ideas in pursuit of addressing multiple sustainability transitions in a (transport) infrastructure construction project"?

This paper aims to answer this question by investigating a recent case about the planning and construction of a railway station which is intended to connect a Chinese city, Jingmen, to two new national high-speed railway lines running across China. This case was chosen because of three unique characteristics. First, the research team had in-depth access to local public professionals who faced multiple sustainability transition policies between late 2018 and early 2019. Second, the timing of this study allowed for actual relevant input from the professionals, as they were in the midst of conceptualizing an integrated design of the railway station before finalizing the project construction plans. This particular timing allowed for the case study to identify issues and difficulties during the actual planning process. Third, the city of Jingmen offers a unique insight into the dealings of local professionals, because the city is not internationally known for any iconic or front-running projects. This makes this case stand out as an 'average case'. Previous studies focused on special and iconic cases of urban sustainability, ranging from mega infrastructure projects, like the bridge connecting Hong Kong, Zhuhai and Macau [11], and 'front-running' cities, such as Dalian [12], Taipei [13], Shenzhen, Beijing and Shanghai [14]. The iconic state of these projects provides them financial resources to undertake these transitions, which cities like Jingmen lack.

This study adopts a Triple Bottom Line (TBL) approach in Sections 2 and 3 to explore the multidimensional character of the transitions more in depth. Following this approach, Section 4 unveils that, in the Jingmen case, sustainability was not fully envisioned by local professionals. Section 5 debates that although multiple policy documents outlined how to implement sustainability or CE, these actually seem to act as 'precooked' silo type initiatives and only specific sectors are expected to pitch in for the specific transition. This creates a cognitive silo for local professionals when approaching them head-on. However, when abstracting the transition focus, the integral nature of ideas makes breaking out of the silos possible. This study found the TBL principle a useful and novel approach 
to break from the silos, because it stresses the interdependence between the various sustainability dimensions and, thereby, offers a useful analytical approach.

\section{Literature Review}

\subsection{Sustainability}

The concept of sustainability evolved throughout the 1970s and 1980s [15]. The often-quoted Brundtland report defined sustainable development as "development that meets the needs of the present without compromising the ability of future generations to meet their own needs" [16] (p. 51). An action plan for a transition to sustainability was introduced five years later at the 1992 United Nations Conference on Earth and Development in Rio de Janeiro as Agenda 21 [17].

At a generic level, sustainable development is oftentimes understood as a practical process in which economy, environment and society are brought together in a balanced way, particularly by reconciling conflicts between these three elements [18]. Sustainability relies on the successful maintenance and enhancement of the three dimensions of sustainability, i.e., environmental, social, and economic resources [19].

Out of these three dimensions, environmental sustainability is perhaps the first one which comes to mind as sustainability. It can be defined as "the maintenance of important environmental functions, and hence the maintenance of the capacity of the capital stock to provide those functions" [20] (p. 637). Environmental functions refer to environmental services, including spatial functions, waste disposal, natural resource supply and life support [21]. Second, with economic sustainability, it represents that "an economically sustainable system is able to produce goods and services on a continuing basis" [22] (p. 64). It means the use of various strategies for employing existing resources optimally so that a responsible and beneficial balance can be achieved over the longer term [23]. Lastly, social sustainability is defined by "identifying and managing business impacts on people" [24]. Relevant values stemming from social sustainability include "equality, diversity, democracy, and interconnectedness" [25].

The interdependence among these separate dimensions has been coined as TBL by John Elkington in the late 90s in his book Cannibals with Forks: the Triple Bottom Line of 21st Century Business (1997). Figure 1 depicts this interdependence of the three sustainability dimensions, as three encircled areas which partially overlap like a Venn diagram. The overlaps represent the interdependence among the dimensions in order to reach sustainability. If a measure is plotted in the area with an overlap between two dimensions, then benefits are sought for both dimensions. For example, if a measure seeks improvement for both social and environmental sustainability, then it could be environmentally-friendly and socially responsible but perhaps very expensive economically. The three dimensions have been used as separate and overlapping foci to improve sustainability in various studies [19,26-29], as performance indicators [30] or a set of desired outcomes [31,32].

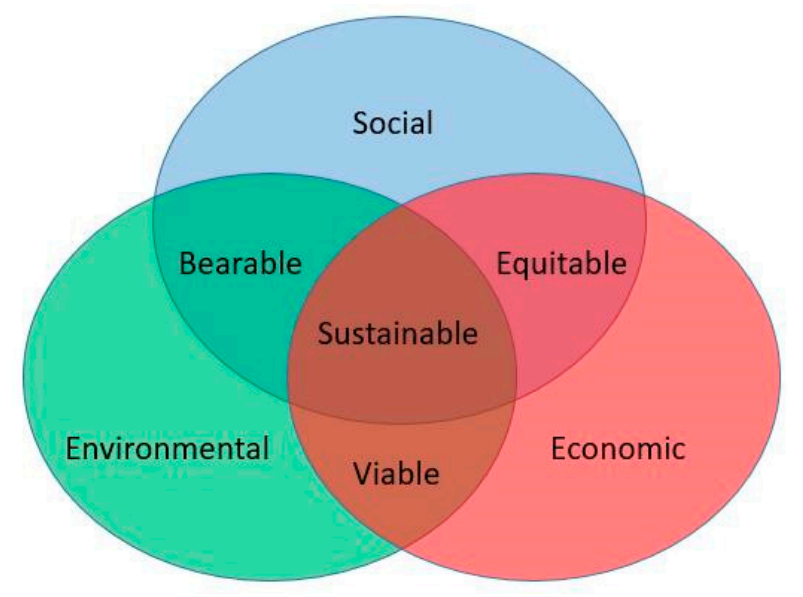

Figure 1. The Three Dimensions of Sustainability. Based on [33]. 
Ultimately, the TBL reasons that half-hearted improvement suggestions are in fact not fully sustainable. In fact, Figure 1 illustrates that an idea or a measure is only truly sustainable if it aims to benefit all the three dimensions in the center. Following this line of reasoning, Ahi and Searcy [29] (p. 2882) claimed that "implementing sustainability requires a TBL approach" and, thereby, we suggest that true sustainability is interdependent on each of these dimensions simultaneously.

Thus, according to the TBL perspective, the ultimate sustainability goal can be considered to lie at the intersection of the three dimensions (see Figure 1). Both in practice and in research, work has focused on the development of methods to assess the desirable outcome of sustainability. In practice, standards are actually conceived and shared on the overlap of the three dimensions by the Global Reporting Initiative (GRI) reports, for infrastructure among other sectors [6]. In science, assessment models are known as Sustainability Impact Assessments (or SIAs) [31,32], like for underground infrastructure construction projects [34]. In essence, the dimensions enable users to assess in what way changes contribute to and/or affect sustainability.

\subsection{Sustainability Transitions}

Various sustainability transition movements can be identified worldwide. Some are clearly driven by global agreements and agendas, like the Sustainable Development Goals (SDGs) of the United Nations (UN) and the Paris Accord [35]. For example, the SDGs form a global agenda for international cooperation on sustainable development since 2015 until 2030 [36]. Apart from these international agreements, national laws and programs also mobilize a multitude of sustainability transition movements for public professionals. Sometimes these transition movements are aligned as part of 'national' strategies, but sometimes they also 'behave' independently from each other.

In China, governments at the national, regional and local levels establish more specific agreements, agendas or even more concrete programs, policies or enact specific laws. The National Sustainable Development Report of P. R. China introduces the general thoughts of the Chinese central government for moving towards sustainable development [37]. Likewise, in Europe, there is A Sustainable Europe 2030 Strategy, an overarching strategy-the successor of the EU2020 strategy. This strategy defines both interim and long-term targets and timelines over and above short political cycles, laying out Europe's vision of a sustainable future until and beyond Agenda 2030 [38].

There are various ways in which policies and programs can contribute to the pursuit of sustainability transitions, for example, the energy transition [39-41] and digital transition [42]. Perhaps one of the most notable paths is the movement toward CE [16]. In scientific debates, CE has been conceptually compared to sustainability and recognized as pursuing the same goals [43], although not entirely the same [44]. Research has recognized that CE practices overlap with multiple SDGs [45]. With regard to the TBL, it is regarded that $\mathrm{CE}$ adheres to both economic and environmental dimensions of sustainability [7].

In sum, there are various sustainability transition agendas. Each of these stimulates and pushes professionals into various directions, oftentimes contributing to different transition movements. This creates a massive challenge for public professionals who have to abide to local and national government regulations when working on projects, in particular the multitude of sustainability transitions which remains unresolved in the academic debate on implementing sustainability $[9,10]$. The next section reviews the more delicate challenges and state-of-the-art knowledge about the integration of these agendas into infrastructure planning and construction.

\subsection{Sustainability in Infrastructure Planning and Construction}

Infrastructure projects represent major investment and construction initiatives with attendant environmental, economic and societal impacts across multiple scales [46]. It is considered important that these projects adhere to the principles of sustainable development [47].

A lot of research that focuses on sustainability and infrastructures deals with sustainability appraisal, assessment/evaluation [30,48-51], indicators [47,52], and frameworks [46,53,54]. Amasuomo et al. [55] 
reviewed sustainable development and sustainability approaches for infrastructure projects in the United Kingdom. In essence, it appears important that sustainability gains a foothold in infrastructure projects.

More specific literature on incorporating sustainability inside transport infrastructure experiences similar developments, like the creation of sustainability assessment/evaluation [56,57] and frameworks/approaches [58]. Incorporating sustainability inside transport infrastructures can be quite challenging. On this point, Goh and Yang [59] provided insights into the major challenges of implementing sustainability in highway project development in terms of financial concerns and obligations from a stakeholder perspective.

An interesting perspective with regard to understanding sustainability inside infrastructure projects has been proposed and investigated by Mostafa et al. [60]. They conceived, from a stakeholder-centric perspective, how each of the sustainability dimensions can be properly captured. In their stakeholder-sensitive, social welfare-oriented sustainability benefit analysis (S3) model, they developed a method that shows how stakeholder input affects the planning and design of infrastructure systems and what collective benefits result from tension across the social, environmental, and economic sustainability dimensions. In essence, it suggests that the TBL framework forms a plausible approach to study idea generation and the potential of infrastructure interdependencies. In the next section, we construct an analytical approach based on the TBL to empirically investigate how professionals envision "sustainability ideas" in pursuit of addressing multiple sustainability ambitions in infrastructure development.

\section{Case Materials and Methods}

This section introduces the case material and the methods used. First, the background to the project case of a high-speed railway station in Jingmen, called Jingmen West Railway Station (JWRS), is briefly described. Thereafter, it is elaborated how this case is addressed with regard to data collection and analysis. Some key methodological choices and details are provided.

\subsection{Background to the City of Jingmen and the JWRS}

Jingmen is a city like hundreds of others in mainland China. It is a "Fifth-tier" city (According to one Chinese media (Yicai), of the 338 listed cities in 2017, Jingmen is one of the 129 "Fifth-tier" cities, ranking after four "First-tier" cities, 15 "New First-tier" cities, 30 "Second-tier" cities, 70 "Third-tier" cities and 90 "Fourth-tier" cities. The list is based on the "concentration of commercial resources", "the extent of transport hub", "the vitality of citizens", "the diversity of lifestyles" and "the flexibility of the future" of the cities [61]). Figure 2 shows that Jingmen is located in the central province of Hubei. From a socio-economic perspective, Hubei Province mirrors China on average. Hubei's Gross Domestic Product (GDP) per capita (52,458 RMB in 2016) closely resembles the national average level (53,935 RMB in 2016). Jingmen is located in central Hubei and has 1,625,000 residents in the city, and 2,901,300 in the wider metropolitan administrative region (2016). Jingmen's GDP per capita is 52,470 RMB (2016).

A key characteristic of Chinese cities including Jingmen is the central authority of the Municipal Party Secretary and the Mayor. These powerful local actors play an important role in the local governance context. Local government departments and agencies are hierarchically placed under these authorities.

As part of a larger sustainability transition, the city of Jingmen faces various infrastructural planning, design and construction issues in relation to sustainability. For example, it pursues sustainable transport solutions inside the city and simultaneously aims to redevelop its industrial parks in light of the city's circular economic agenda. Amidst these challenges, the city is also faced with the design and construction of the JWRS.

Jingmen plans to build the JWRS with five railway platforms and eleven railroad tracks. Such a station is typical in China. The local officials regard JWRS as an important transport infrastructure project for the city. The JWRS will form a crucial hub in the national high-speed rail network. 
Two crucial Chinese high-speed railway lines (the Hohhot-Nanning High-Speed Railway and the Shanghai-Chongqing High-Speed Railway) will connect in the prospective location.

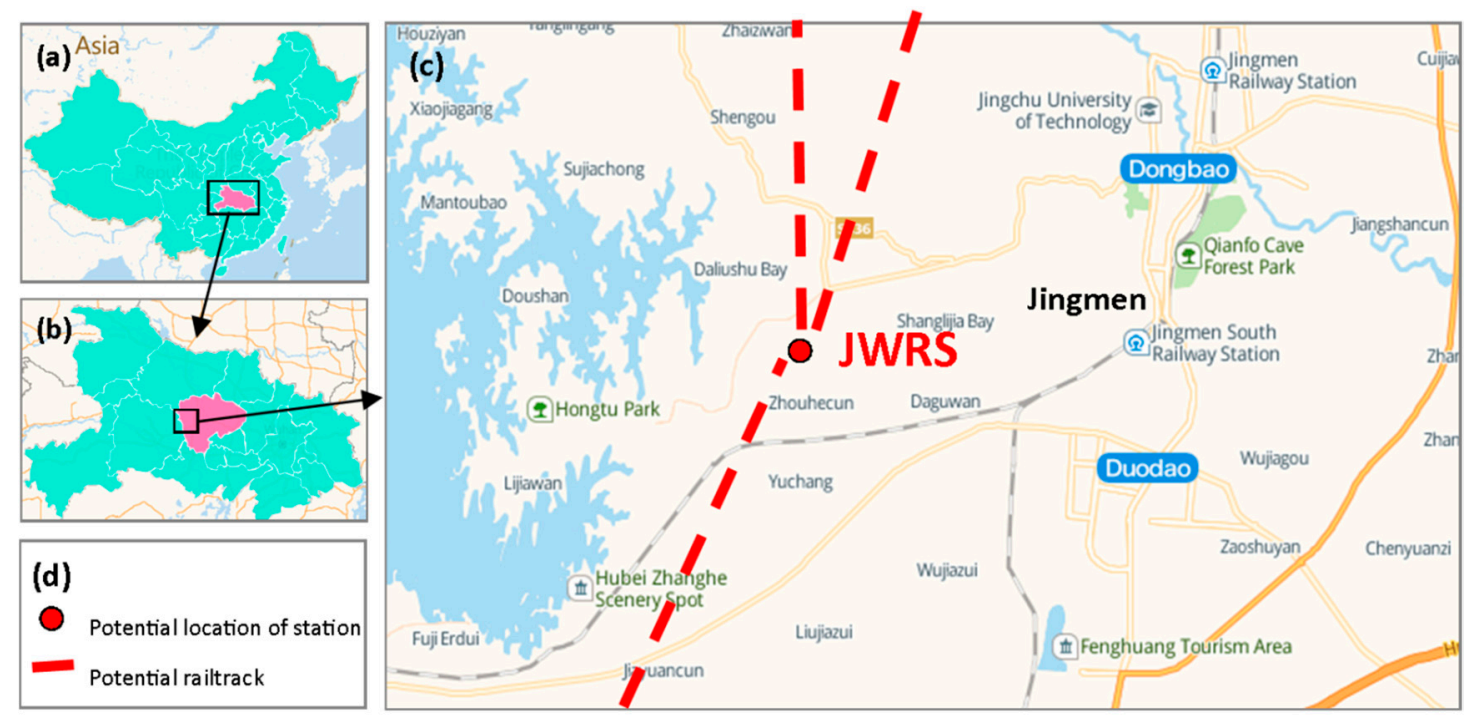

Figure 2. The Location of Jingmen within Hubei Province and China (The red circle stands for the general location of the Jingmen West Railway Station (JWRS)). (a): China; (b): Hubei; (c): Potential location of JWRS and its surrounding areas; (d): Legend for (c).

When the case study period commenced, the JWRS was in its planning stage. The project posed a unique first-hand challenge for city professionals in dealing with multiple sustainability goals and sustainability transitions. The planning, design and construction of the railway station and its surrounding areas are influenced by the necessity of the city of Jingmen to reduce its $\mathrm{CO}_{2}$ emissions. Furthermore, the city is designated as one of the CE Demonstration cities in China [62], which brings additional sustainability goals. The authors were aware of this before going to Jingmen. These various sustainability transitions provide an excellent opportunity to observe and understand how urban infrastructure projects are typically realized in the Chinese governance context and to what extent these play a role in searching for measures and ideas that can achieve sustainability.

In first contacts with the city of Jingmen, in preparation of the case study, a few initial interviews were held with three public professionals (from the Jingmen Urban and Rural Planning Bureau and the Reform and Development Commission of Jingmen). The interviews proved indispensable in determining the right focus for the study. It became clear that although Jingmen is a CE Demonstration city, implementing CE in the planning, design or construction of new infrastructures appeared to be too revolutionary. This provided the preliminary indication that local professionals are not always aware of the potential value of CE or ready to adopt CE ideas into transport infrastructure planning, design and construction. Hence, it confirmed the suitability of a more generic enquiry on sustainability to disclose ideas toward sustainability from local professionals.

In short, the research focuses on, for a new transport infrastructure project, what potential opportunities to improve sustainability local public professionals envision. A few methodological choices must be addressed in order to clarify the scope, focus and outcome of the case study.

\subsection{Methodology to the JWRS Case Study}

The planning and design of the JWRS is approached as a case study. This means that the information obtained pertains to the study object itself and its context. The research was conducted on site in the city of Jingmen, so that the research could be conducted in close collaboration with representatives from the local government. As a result of this, the research could benefit from relative direct access to sources of information from local government organizations involved in the project. 
Via this way secondary literature and supportive documents could be obtained and interviews could be organized.

The object of study was separated in content-based and context-based data collection practices. First, it appeared that the development and planning process were different for the railway station and its nearby surrounding areas. This created an opportunity where "sustainability ideas" could affect either the station, the surrounding area or both. The focus of the research project was thus deliberately scoped to encompass both JWRS and the surrounding areas of the station.

First, this study involved a review of policy documents in order to understand which programs, laws and policies were directly or indirectly involved in the JWRS development and the sustainability transitions. The data were obtained from Chinese National Government, Hubei Government and Jingmen Government via their government websites. These provided information regarding the transport sector, planning of the station and sustainability transitions.

The search for policy documents resulted in a total of 11 documents, from the local, regional and national governments in China. These documents were searched (in Chinese) and reviewed for implications of sustainability transitions, CE, general planning and transport/railway sector that could affect the planning, design and construction of the JWRS and its surrounding areas. The overview of the policy documents is shown in the Results Section.

Next, interviews were conducted with representative public professionals, whose work is related to the JWRS and its surrounding areas. The "sustainability ideas" that these actors envisioned for the whole JWRS project were obtained. To collect and analyze the data from these interviews, we used the TBL as an analytical framework to assess the focus of suggested improvements. In the analysis stage, we plotted the responses of the professionals. The three TBL dimensions enable us to analyze how public professionals view sustainability and what opportunities for improvement they identify.

The interviews were conducted by means of a TBL-oriented line of enquiry, splitting specific questions up into environmental, economic and social sustainability. Since it was reckoned that the development and planning of the railway station and its surrounding areas were separate, both these objects were objects of enquiry. The questions in the interview were prepared with a focus on obtaining ideas for improving the sustainability for the JWRS and its surrounding areas. The interviews were semi-structured to allow for multiple ideas to surface per question.

The interview protocol consisted of the following open-ended questions:

Q1: What do you think is important for the environmental sustainability of Jingmen West Railway Station?

Q2: What do you think is important for the environmental sustainability of the development of surrounding areas of Jingmen West Railway Station?

Q3: What do you think is important for the economic sustainability of Jingmen West Railway Station? Q4: What do you think is important for the economic sustainability of the development of surrounding areas of Jingmen West Railway Station?

Q5: What do you think is important for the social sustainability of Jingmen West Railway Station?

Q6: What do you think is important for the social sustainability of the development of surrounding areas of Jingmen West Railway Station?

The interviews were conducted mainly with public professionals from the city of Jingmen. A few choices with regard to the selection of interviewees warrant justification. For the case, it was important to enquire professionals from the departments and agencies which have a role in the development of the railway station and the surrounding areas. Therefore, local government agencies with this focus were identified and selected. Second, since the JWRS was in its planning stage, external companies or organizations were not yet involved in the design and planning of the project. Therefore, the selected respondents were predominantly from various government departments and branches within the city. In addition, an interviewee from a local university, Jingchu University of Technology, was added to the set of respondents to obtain a more comprehensive view of the JWRS and its surrounding 
area. This resulted in a mixed background of interviewees, from engineers to policy makers. Figure 3 shows the various departments/branches/agencies of public professionals who were selected for the interviews.

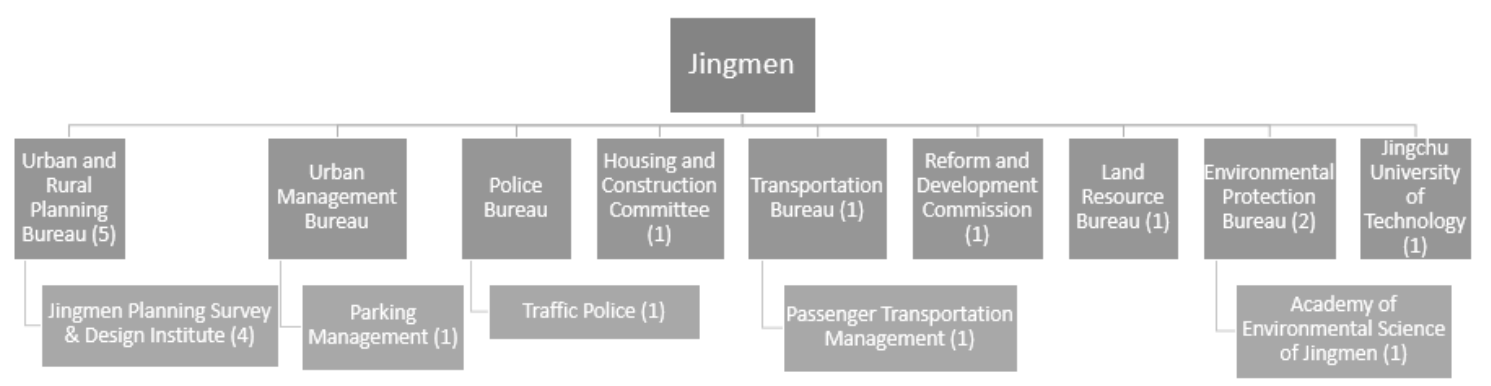

Figure 3. The Working Places of the Interviewees in Jingmen. The numbers in the parentheses represent the number of interviewees in certain department/branch/agency.

A total number of twenty semi-structured interviews were held in Jingmen with representatives from local governmental bodies and public research institutes. The interviews lasted from half an hour to one hour and were conducted in Chinese. The interview period was concentrated within two weeks so that the information obtained from the interviewees were referring to roughly the same timeframe. Nineteen interviews were recorded and transcribed with the explicit agreement of the interviewees. One interview was summarized with written notes only. Core information was extracted from the transcripts and notes and then was translated into English.

Since the line of enquiry was prepared along the TBL-based structure, the TBL was also used as the actual data structure for the analysis. Content analysis is commonly used for analyzing qualitative data $[63,64]$, and therefore it was used to analyze the information from the interviews. Thus, the analytical focus of these interviews was novel. Ideas were extracted from transcripts pertaining to the relevant dimension of sustainability and objects of study. In this way, a list of 263 "sustainability ideas" was obtained. This list was then reviewed to eliminate any reoccurrences. These were earmarked as reoccurring ideas. For example, one interviewee said "pay attention to the protection of water quality", while another expressed "pay attention to the protection of local water resources nearby"; these ideas were classified as similar ideas and subsequently merged together. The resulting associative structure contained ideas of the environmental, economic and social dimensions of sustainability for both the station and the surrounding areas.

To provide more insight into the associative structures of the ideas with the TBL framework, the ideas were mapped in a social network graph. The mapping was provided by the software Pajek, a social network graph analysis package [65]. The analysis itself is a 2-mode social graph, which provides an overview of the relations between "sustainability ideas" and the dimensions of sustainability. The overview of the "sustainability ideas" was mapped in the TBL structure for the railway station in Figure 5 and for the surrounding area of the JWRS in Figure 6 in the Results Section.

\section{Results}

The results are shown in two phases. First, we reviewed the most essential elements of the policy documents with regard to the sustainability requirements, $\mathrm{CE}$ and transport infrastructures. This part contains the review and analysis of government transport, planning, sustainability and CE policies (Section 4.1). Section 4.2 discusses the interview results with regard to the relation between the "sustainability ideas" and the dimensions each idea is associated with.

\subsection{Policy Regarding Sustainability Transitions, CE, Transport, Planning and the JWRS}

Since 1992, China has set down sustainable development as a basic national strategy [66], while $\mathrm{CE}$, as an official national development goal and China's basic national policy, was put in law $[67,68]$ 
and China issued more than 200 CE-related national standards after 2008. Following a top-down way, governments of different levels all over China promulgate their policies gradually.

Jingmen was designated as the National CE Demonstration Pilot City in 2007 (the only one in Hubei Province); in 2014, Jingmen qualified to become one from the list of National CE Demonstration Cities.

Figure 4 maps the various policy documents relevant to this study. They were produced by the three levels of government, i.e., the national level (China), the regional level (Hubei Province) and the local level (city of Jingmen). The figure plots the various documents and the level of government that issued the document and the corresponding releasing year.

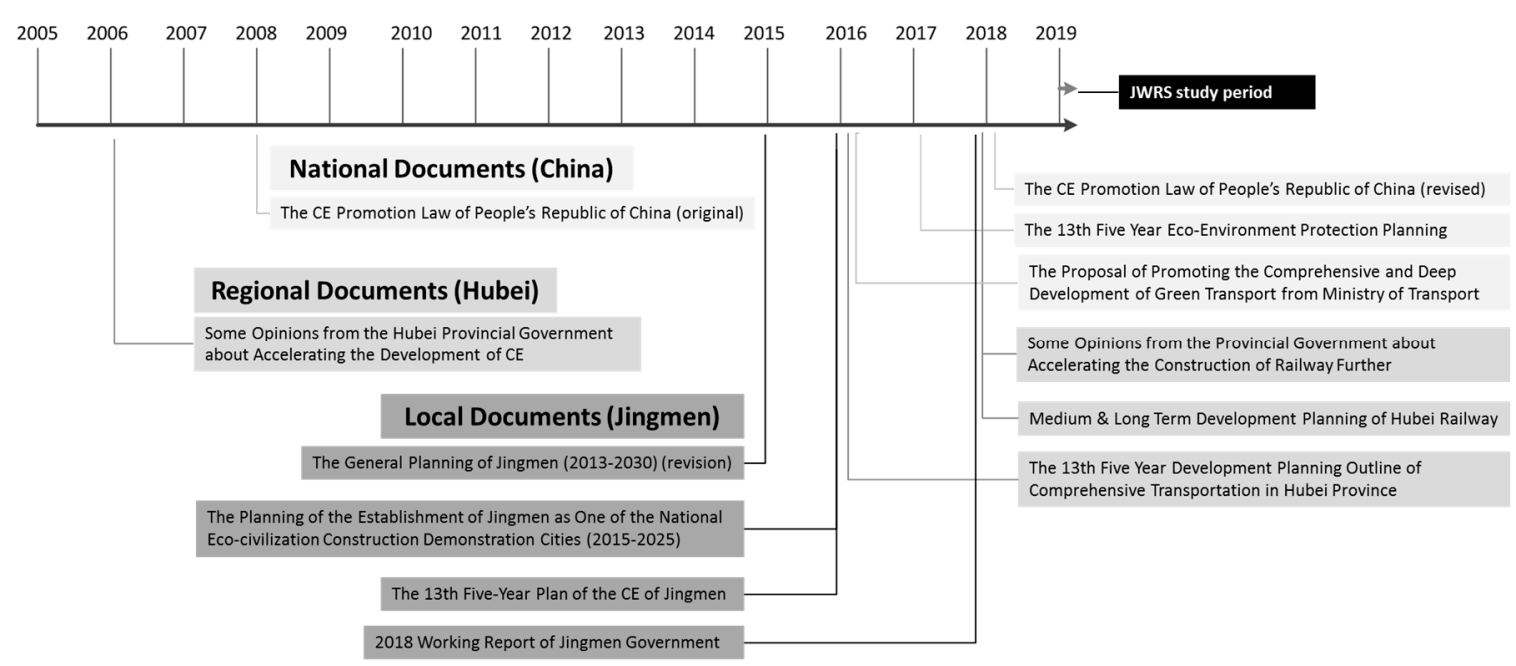

Figure 4. Documents Relevant for Sustainability Transition, Circular Economy (CE), Planning and Transport Infrastructure.

\subsubsection{National Policy Documents from the Chinese Government}

At the national level, several key documents which contain requirements and policies for $\mathrm{CE}$ can be identified. They are the 'CE Promotion Law of People's Republic of China' in 2008, which was revised in 2018, the Eco-Environment Protection Planning, approved by the State Council in 2017, and the Proposal of Promoting the Comprehensive and Deep Development of Green Transport from the Ministry of Transport.

The CE Promotion Law is an important piece of national legislation which connects sustainable development and CE transition throughout the country. The law claims the development of $\mathrm{CE}$ facilitates resource efficiency and environmental protection [68], and provides guidelines to develop $\mathrm{CE}$ as a strategy to facilitate policies of lower level governments. The law states that $\mathrm{CE}$ is promoted when regional governments make annual plans about civil economic and social development or when departments make plans for environmental protection or science and technology. An example of an environmental protection measure could be the organization of the resource use among companies in industrial parks. The law supports and encourages local governments to engage in these projects and enables finance, investments and governmental procurement of these initiatives, like science and technology development and educational activities.

The 13th Five-Year Eco-Environment Protection Planning was issued in 2016 by the State Council. It outlined various requirements in light of sustainability. For instance, the intention of the Chinese government to execute the UN's SDG agenda for 2030 is one of them. It specifically elaborated on the development of agricultural technologies (e.g., water-saving, circular and organic processes) [69].

In 2017, the Chinese Ministry of Transport proposed to promote the development of new green transport solutions. It proposed to change the transportation services and develop a green, circular and low-carbon transportation system [70].

The documents illustrate that the focus on sustainability and CE is embedded strongly in diverse high-level Chinese policies and is considered of national interest. Plans and proposals typically zoom 
in on developments in the agricultural and industrial sectors. In the documents, an explicit linkage is made between sustainability and circularity.

\subsubsection{Regional Policy Documents from Hubei Province}

At the regional level, several policy documents were found to be of considerable interest. The Opinions from the Hubei Provincial Government about the Acceleration of CE from 2006 preceded the national CE promotion law and provided a detailed analysis of $\mathrm{CE}$ transition that was needed. For example, it discussed the setup of a scientific $\mathrm{CE}$ assessment indicator system and accounting institutions. Also, it already iterated the need for making and realizing CE development promotion plans, by means of technological support systems, advisory service systems and provincial financing schemes into science and education [71].

In relation to the planned railway station, Hubei Province issued three important policy documents. One is Hubei's 13th Five-Year plan towards a Comprehensive Transportation System (2016). This document established a priority on ecological and green development of the whole process of transport planning, design, construction and management. The aim was to accelerate the construction of a green, circular and low-carbon transportation system [72].

In 2018, two further documents directly influenced the construction of a provincial railway system. First, there were some opinions iterated by the Hubei Government to accelerate the construction of a railway network with a focus on the sustainable development of the railways. Second, a mediumand long-term development plan from the Hubei Provincial Development and Reform Commission confirmed this goal for the railway sector.

Interestingly, Hubei Province, via its policy documents, shows a strong connection to CE transition, albeit at a very generic level. For specific infrastructure plans on railways, the reviewed documents suggest a broadening of the efforts to implement sustainability.

\subsubsection{Local Policy Documents from Jingmen}

At the local level, a handful of documents which were related to the JWRS case were reviewed. In 2015, a general planning document for Jingmen was issued for the active period until 2030. In this plan, Jingmen called for sustainable development plans and referred to the protection and rational use of natural resources (water, land, energy, etc.). It also stressed on the need to realize a sustainable transport system, which means an efficient and complete set of transportation connections and facilities. CE was mentioned to a far lesser extent, only as a means of facilitating energy savings and emission reduction.

In 2016, two developmental plans were issued specifically to introduce and implement the national programs to enhance the sustainable character of Jingmen. First, a plan was issued which made Jingmen to become a 'National Eco-civilization Construction Demonstration City' for the period 2015 until 2025. This indicated that the city had decided to focus on environmental protection and the construction of an eco-city with the urban-rural sustainable development. Additionally, the plan for this label called for Jingmen would task itself with the ambition to reduce the environmental pollution via sustainable consumption, i.e., more green products and less waste disposal.

The 'Eco-civilization Construction Demonstration City' program also carried CE ambitions. This policy document focused particularly on the construction of a CE platform for Jingmen's various industrial parks (e.g., Chemical Circular Industrial Park and the Electric Waste Circular Industrial Park in Jingshan (a subordinate county of Jingmen)). Furthermore, the program also mentioned initiatives such as enterprise loans for green technology development and the development of rural regions like the 'China Agricultural Valley'.

The second plan was Jingmen's Five-Year plan, in which it stated its ambitions for CE and its desire to become a 'CE Demonstration City' in 2016. The plan noted that new projects needed to apply principles of CE. However, the plan did not specify which type of projects were meant. It appeared to refer mostly to enterprises and demonstration parks and to focus on resource efficiency and financial and fiscal possibilities to support CE developments in these areas. 
In 2018, Jingmen issued a working report in which it positioned itself as a CE Demonstration City. The report again focused on recycling and reuse initiatives in the chemical and agricultural sectors.

It is remarkable to note that with regard to sustainability, the local government recognized the task in hand to be related to transport and railway system. However, with regard to CE, the local documents do not recognize the value in construction works of transport infrastructures such as railway stations, even though Jingmen is actually considered to hold two positions as a demonstration area, i.e., a CE Demonstration City and the Eco-Civilization Construction Demonstration City/County (the Jingshan County in Jingmen).

In summary, The CE Promotion Law of People's Republic of China notes that developing CE is necessary to realize sustainable development. Generally, national policies identify main directions, while local policies specify measures in more detail. However, in general planning or CE-related policy documents, transport infrastructure was not specifically mentioned. While in the transportation related policy documents, sustainable development or $\mathrm{CE}$ are only briefly mentioned. This policy analysis explains why CE is not embedded into Jingmen's transport infrastructure projects as was expressed by the three officials from the Reform and Development Commission of Jingmen and Jingmen Urban and Rural Bureau. Although Jingmen is one of the CE Demonstration Cities in China, CE implementations are mainly focused on chemical, agricultural and service industries, the so-called "traditional" CE practice areas.

\section{2. "Sustainability Ideas" Envisioned for the JWRS and Its Surrounding Areas}

For the JWRS case specifically, the "sustainability ideas" are portrayed in two social network graphs, one for ideas pertaining to the railway station itself in Figure 5 and the other for the surrounding areas of the JWRS in Figure 6. The size of the nodes and the width of the lines are proportional to the amount of times the respective ideas were proposed by the interviewees.

4.2.1. Top "Sustainability Ideas" Mentioned according to Jingmen Professionals for the JWRS and Its Surrounding Areas

Judging from the size of the nodes, the railway station and its surrounding areas both generate a number of ideas that were mentioned at least six times by interviewees (see Table 1). With regard to the JWRS itself the idea that was mentioned most often was 'pay attention to water quality/wastewater' (10 times out of 20 interviewees). This is, in itself, not surprising since the JWRS is planned quite close to the local Cheqiao Reservoir. However, the ideas were 'only' associated with environmental sustainability and not very interdependent in terms of sustainability. Professionals seemingly provide priority to develop measures that help reduce and treat wastewater and avoid a negative environmental impact on the reservoir.

The second top idea is 'pay attention to the compensation of land acquisition', which considers the impact of the JWRS plans on residents. Some must be relocated for the railway station project. The Jingmen professionals reckon that local residents who stand to lose their land as a result of current plans should be (adequately) compensated. Interestingly, apart from these two generic 'ideas', very specific elements with regard to the JWRS were mentioned as source of ideas. The overall effect is that the 'ideas' of the professionals are only focused on a single dimension of sustainability.

With regard to the surrounding areas of the JWRS, three ideas stand out, i.e., 'arrange good affiliate facilities' (nine calls), 'pay attention to plants' (seven calls) and 'distribute surrounding industries rationally' (six calls). These ideas clearly pertain to improving the surrounding areas (with green plants and facilities that serve social and economic functions). In contrast to the ideas of the railway station, these ideas were more interdependent between sustainability dimensions. 
Table 1. Top Calls from Local Professionals Regarding Jingmen West Railway Station (JWRS) and Its Surrounding Areas ${ }^{1}$.

\begin{tabular}{|c|c|c|c|c|c|c|c|}
\hline \multirow{2}{*}{ Rank } & \multirow{2}{*}{ Sustainability Idea } & \multirow{2}{*}{$\begin{array}{c}\# \\
\text { Total }\end{array}$} & \multicolumn{2}{|c|}{ \# per Object } & \multicolumn{3}{|c|}{ \# per Dimension } \\
\hline & & & JWRS & SA & SOC & ENV & $\mathrm{ECO}$ \\
\hline 1 & Pay attention to water quality/wastewater & 10 & 10 & - & - & 10 & - \\
\hline \multirow[t]{2}{*}{2} & Arrange good affiliate facilities & 9 & - & 9 & 4 & - & 5 \\
\hline & Pay attention to plants & 9 & 2 & 7 & 1 & 8 & - \\
\hline 4 & Pay attention of the compensation of land acquisition & 8 & 7 & 1 & 8 & - & - \\
\hline \multirow[t]{4}{*}{5} & Distribute surrounding "industries" rationally & 7 & 1 & 6 & 3 & - & 4 \\
\hline & Timely clearing away trash & 7 & 4 & 3 & - & 7 & - \\
\hline & Pay attention to the effects of construction to air quality & 7 & 4 & 3 & - & 7 & - \\
\hline & Conserve energy & 7 & 4 & 3 & - & 5 & 2 \\
\hline \multirow[t]{3}{*}{9} & Pay attention to aesthetics & 6 & 4 & 2 & - & 1 & 5 \\
\hline & Reduce noise & 6 & 6 & - & 2 & 4 & - \\
\hline & Show local characteristics & 6 & 6 & - & 2 & - & 4 \\
\hline
\end{tabular}

1 SA: surrounding areas of the JWRS; SOC: social sustainability; ENV: environmental sustainability; ECO: economic sustainability.

\subsubsection{Interdependence of "Sustainability Ideas" for the JWRS}

Figure 5 shows the "sustainability ideas" associated with the railway station. First and foremost, it can be noticed that no idea has a direct relationship with all three sustainability dimensions. However, there are a few ideas interdependent with two dimensions.

First, in the intersection between environmental and economic sustainability, five ideas were mentioned: 'adopt green building', 'conserve water', 'conserve energy', 'adopt assembly building' and 'well design the station'. The linkage between these dimensions seems to be oriented towards the adoption of modular and green methods for the construction of the station. Additionally, it appears that professionals recognize the conservation of resources as an environmental and economic approach to become more sustainable.

At the intersection between social and economic sustainability, three ideas were mentioned: 'the station cannot be too far away from the central areas of the city', 'pay attention to the services inside the station' and 'show local characteristics'. The interdependence between social and economic sustainability could be viewed as the social-economic function, i.e., the attractiveness of the station to people (including its location) and the services in the station.

The ideas which focused on the interdependence between the social and environmental dimensions of sustainability were only mentioned twice ('reduce noise' and 'reduce consumption of basic farmland'). The professionals seemed to view the relationship between both dimensions primarily as an opportunity to reduce undesirable side-effects, like noise during the construction and operation of the railway station. The part of basic farmland, which must make way if the railway station is located further away from the city center, could be reduced. In that sense, indirectly, the location choice actually affects all aspects of sustainability, as closer to the city center would be better economically, socially (closer to social and economic activities) and environmentally (less farmland lost).

Although no idea met the full TBL, each bilateral interdependence was identified in a number of ideas. Ideas with both an environmental and an economic dimension were strongly related to resource conservation and the application of green and modular building and specific design techniques. Ideas which had both a social and an economic dimension addressed the importance of the social and economic functions of the station and were mainly concerned with the relative geographical location of the station within the city and the extent of services in the station. Ideas with both an environmental and a social dimension focused more on the identification of mitigation measures that could be employed to reduce negative effects like noise and loss of farmland. 


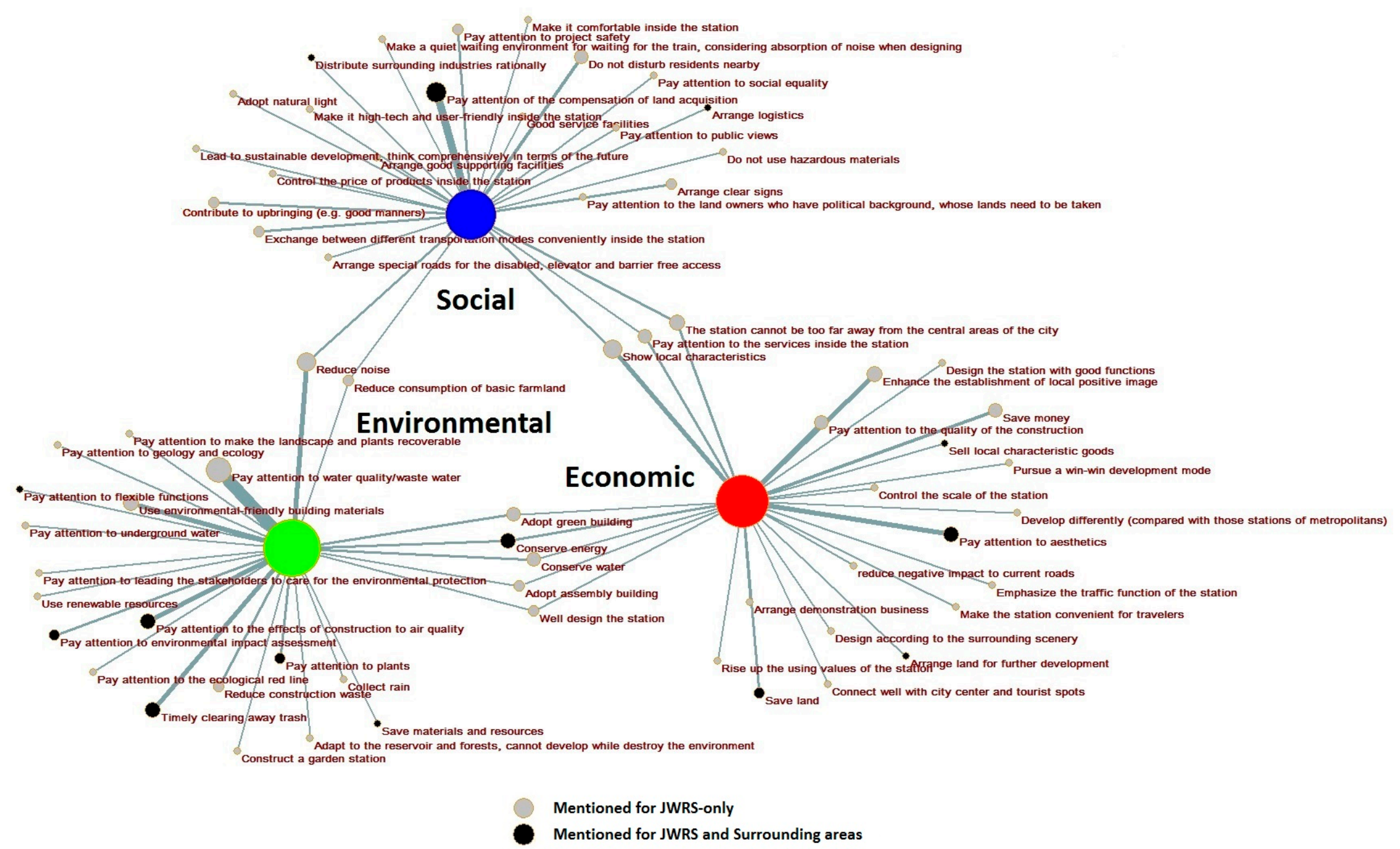

Figure 5. "Sustainability Ideas" Mapped in Relation to Jingmen West Railway Station (JWRS). 


\subsubsection{Interdependence of "Sustainability Ideas" for the Surrounding Areas of the JWRS}

Figure 6 shows the "sustainability ideas" that the interviewees mentioned with regard to the surrounding areas of the JWRS. Like the ideas about the railway station itself, only bilateral relations were found between the sustainability dimensions.

First, three ideas sought to improve social and economic sustainability: 'distribute surrounding industries rationally', 'arrange good affiliate facilities' and 'increase employment'. The professionals envision that the areas surrounding the station should be specifically allocated to businesses to increase employment and economic development. Additional facilities for the station such as parking and transportation facilities were also considered from this perspective.

Social and environmental dimensions of sustainability were connected in two ideas mentioned by the professionals ('make natural sceneries' and 'pay attention to plants'). Both ideas facilitate the inclusion of natural solutions in the design of the surrounding areas (specific flora or local sceneries) for the public.

Only one idea was offered which focused on environmental and economic sustainability ('pay attention to aesthetics'). This in itself is a generic idea which stresses that the overall surrounding areas must be well designed with good appearance (building aesthetics) and ecological aesthetics in mind to attract more people and investment.

Although no idea met the full TBL again, each bilateral interdependence was at least mentioned by the professionals. The ideas which contained social and economic aspects were particularly focused on the management and 'design' of businesses and facilities in the vicinity of the station to increase the attraction of the location and to attract employment for the city. At the intersection between social and environmental sustainability, the professionals focused on the greening of the environment around the station. Finally, only a very generic idea (aesthetics) could be identified at the crossroad between economic and environmental sustainability.

\section{3. "Sustainability Ideas" in Relation to CE in Jingmen}

The policy documents revealed that the city of Jingmen simultaneously pursues two sustainability transitions: as a CE Demonstration City and as an Eco-Civilization Construction Demonstration City/County for one of its specific counties (Jingshan). The local demonstration programs show that, besides the national and regional policies regarding SDGs, CE is considered an important element in Jingmen's sustainability transition. According to Chinese Promotion law for CE issued in 2008, CE is defined by three general types of measures, i.e., reducing, reusing and recycling (3R).

Although the policy documents on transport infrastructure do not mention CE explicitly for railway station construction, the "sustainability ideas" mentioned by the professionals in the case have generated corresponding $\mathrm{CE}$ measures which can be classified according to the " $3 R$ " perspective.

\subsection{1. "Sustainability Ideas" on Reducing}

Four ideas can be recognized as CE measures which seek to reduce the impact of the JWRS construction project, i.e., 'reduce construction waste', 'save land', 'reduce consumption of basic farmland' and 'collect rain'. However, these types of ideas were not mentioned often by the local professionals in relation to the JWRS. The ideas were only mentioned once or twice each.

The ideas on reducing seem to have the strongest link with the environmental sustainability dimension of the railway station. The clearest example of a type of CE measure is the idea to 'reduce construction waste'. The only CE idea that did not belong to environmental sustainability was the idea to 'save land'. This one was actually oriented more to economic sustainability, since saving land would save costs for acquiring this land and relocating the former residents. 


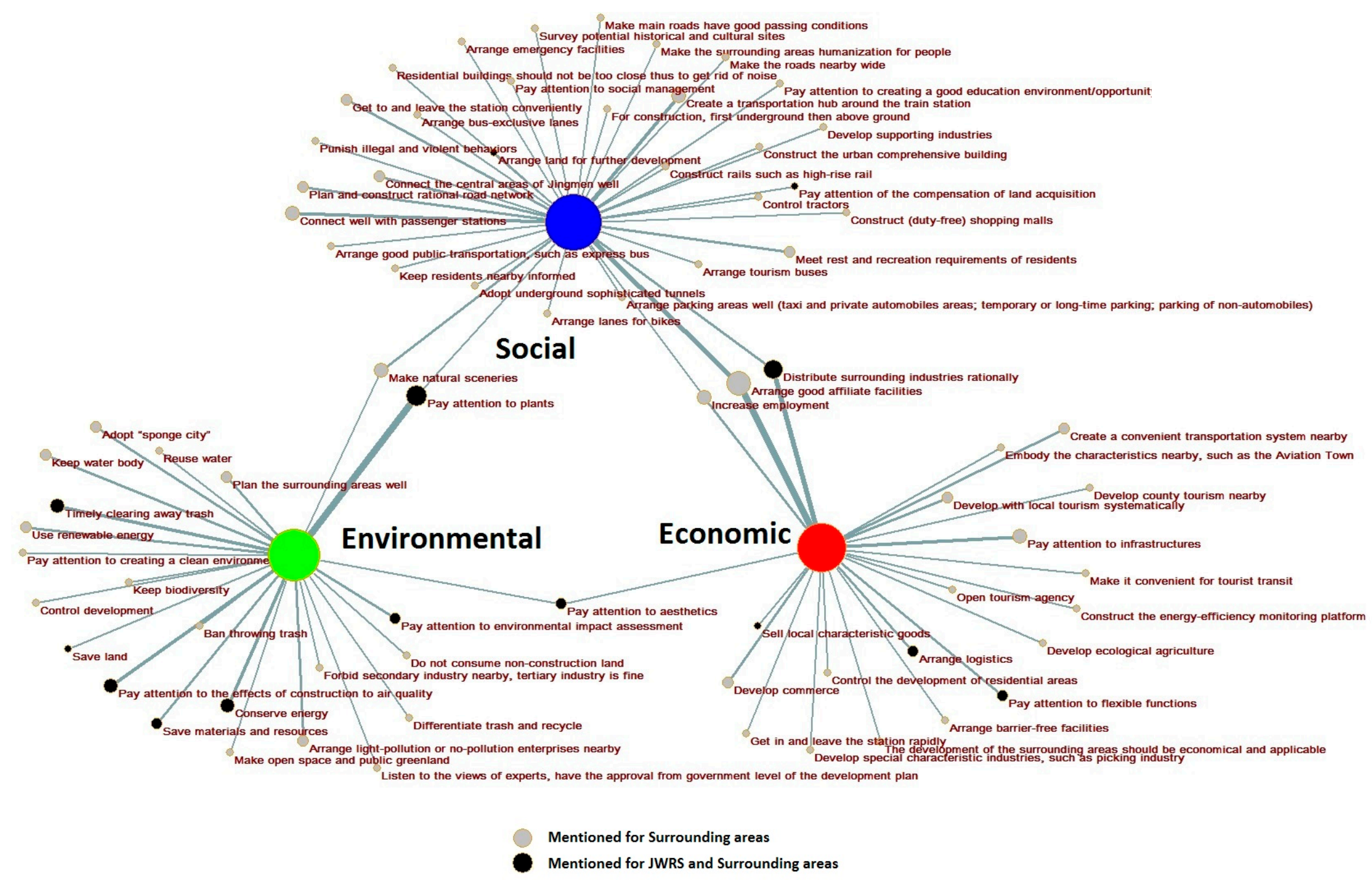

Figure 6. "Sustainability Ideas" Mapped in Relation to the Surrounding Areas of the JWRS. 


\subsection{2. "Sustainability Ideas" on Reusing}

Approximately four ideas could be related to the CE measure on reusing, namely, to 'conserve water', 'save materials and resources', 'conserve energy', and 'reuse water'. All these ideas were only mentioned to a limited extent by local professionals, and they were predominantly present in ideas where environmental and economic sustainability meet: the conservation and reuse of energy, water and other materials.

\subsection{3. "Sustainability Ideas" on Recycling}

Two ideas connect to the CE measure of recycling ('use renewable resources' and 'differentiate trash and recycle'). Both are again associated with the environmental sustainability dimension. The connection to the concept of recycling is also not very strong, because one idea refers to renewable resources more than recycling, and the other idea is just mentioned recycling in relation to trash, without a specific reference on the type of trash.

\section{Discussion}

The Jingmen case has offered a few probing insights. First of all, we are offered a glimpse of multiple sustainability transitions that professionals are faced with. Second, we have gained valuable insights into the conceptualization and realization of sustainability ideas (or measures) in transport infrastructure construction projects, by looking at the TBL and the interdependence between the sustainability dimensions. A few key findings are discussed here.

\subsection{The TBL Principle Interdependence in Practice}

The TBL forms our starting point and identifies true sustainability. The notion of achieving true sustainability appears to lie in the achievement of improvements in all three sustainability dimensions. The principle has become so dominant in scientific understanding of sustainability, that the value of the TBL is unquestioned by some as a prerequisite for implementation [29].

On this note, our case in Jingmen showed an interesting empirical feature of the TBL principle in practice. The case showed that true sustainability simply could not be envisioned by local professionals if they were conceptualizing a sustainable railway station and its surrounding areas (Figures 5 and 6). Not a single idea actually overlapped all the three dimensions of sustainability. Furthermore, only a few bilateral connections could be found. The ideas that overlapped with paired dimensions actually had quite a clear and direct set of characteristics on how these pairs were linked, for example by means of conserving resources and adopting new technologies.

\subsection{Transitioning in Silos}

China has become known as a country which invests heavily in sustainability transitions [73]. In the case of Jingmen, we found that sustainability goals were indeed mentioned in national and regional policy documents both for SDGs and for CE. The transition was recognized in the considerations of the city and its proposed projects and earned Jingmen a demonstration status in two sustainability programs. At the city level, it was awarded the CE Demonstration City status.

Interestingly though, the overarching national and regional policies at the local level seem to produce 'precooked' silo type initiatives, and only specific sectors are expected to pitch in for the specific transition. Most notably, regional policies consider CE as a resource efficiency effort for industrial parks and agricultural applications. In addition, the regional government earmarked the transport infrastructure towards sustainability via its policy focus on SDGs. At least on paper, as a result of this singular policy, a new cognitive silo appears to be born.

This is actually corroborated by the preparation of our case and the analysis of the "sustainability ideas" in relation to the Chinese CE promotion law. First, the preparation period found Jingmen reluctant to combine $\mathrm{CE}$ transition with the railway station project. Interestingly, we were told by one 
public official that adopting CE for a transport infrastructure project was considered too revolutionary by the city policy makers. Second, the "sustainability ideas" from public professionals were relatively weakly recognized as related to $\mathrm{CE}$.

These insights show that the hierarchical introduction of transition(s) as in current practice in China creates a cognitive silo for local professionals when taking on transport infrastructure projects head-on. However, when the transition focus is being laid before local professionals in more abstract terms, the integral nature of ideas makes breaking out of the silos possible. The TBL principle which stresses the interdependence between the various sustainability dimensions provides a useful analytical approach to achieve and analyze this.

\subsection{Breaking the Silos with the TBL}

In literature, $\mathrm{CE}$ is portrayed as the explicit connection between environmental and economic sustainability dimensions [74]. It is also recognized strongly connected to the SDGs [43,45]. Especially, Schroeder [45] identified the extent to which CE practices are relevant for the implementation of the UN's SDGs.

In contrast to the existing literature, this case study revealed that $\mathrm{CE}$ is quite strongly related to environmental sustainability, but only weakly related to economic sustainability in the perception of local professionals. This finding is based on the limited set of CE relations, which we identified in the "sustainability ideas" proposed by the public professionals, who predominantly focused on "reduce" and "reuse".

This study, therefore, paints a picture of CE only being relevant to achieve environmental sustainability. However, it is worth noting here the addition of costs could unravel the economic sustainability of the CE option more clearly. Explicating the cost and benefit relation more explicitly would actually help breaking the transition in silo concept, particularly by focusing on the TBL approach.

\section{Conclusions}

There is still a long way to go for infrastructure construction projects in China to fully seize the TBL principle as the case study about JWRS showed. On the one hand, the findings of our research are quite remarkable for sustainability transition, considering the volume and importance of transport infrastructure constructions. On the other hand, this research shows the institutional complexity which (partly) explains the 'cognitive silo' in which local professionals find themselves in the planning of an infrastructure project. These, along with the relative rapid pace with which infrastructure projects are planned and subsequently realized in China, explain how CE does not seem to be embedded in current infrastructure construction projects. One way in which a more 'open' perspective towards sustainability and in particular CE could be pursued among professionals is to understand the interdependent impact of a measure taken in a project by considering its triple effect, both intended and unintended. A more specific focus on interdependencies could actually stimulate the realization of true sustainability effects by inspiring professionals to focus on integral considerations in projects. These could be made tangible in possible trade-off relations of the triple effect of a measure via, for example, life cycle assessment (LCA) methods (environmental and social LCA and life cycle costing) [75].

In the specific circumstances of the Jingmen case, we explored the measures local practitioners considered about how to make a typical transport infrastructure project, a railway station together with its surrounding areas more sustainable. The TBL served as a framework to guide our data collection and interpret the data. Currently, CE mainly plays a role in views of professionals in terms of improvement of environmental sustainability. However, CE deserves a more important position in infrastructure projects among all sustainability dimensions: environmental sustainability as well as economic and also social sustainability. Furthermore, organizations and professionals could benefit from a more open attitude and more systemic way of thinking about infrastructure projects to recognize more sustainable opportunities (including technological improvements such as Building Information Modeling [76]) during the planning, realization, and operational phase (by far the longest period) [77]. 
Furthermore, the various administrative and policy levels could contribute towards the realization of more sustainable outcomes by aligning or even integrating the various sustainability strategies. We suggest that the central Chinese government could stimulate $C E$ and sustainability in infrastructure construction projects by providing more integral and clearer policy guidance to lower-level governments. At the same time, local professionals in cities like Jingmen could be challenged to broaden their perspectives and take the lead in the implementation of $C E$ in more urban infrastructure development. For a big transport infrastructure like the JWRS, local professionals, especially policy makers, should have a strategically panoramic view to make rational decisions towards sustainability after integrated and systematic considerations.

Further research could follow up and consider the challenges for CE between the planning and realization phase of infrastructure projects. It would be interesting to reuse the list of "sustainability ideas" summarized in the current article after the construction of the JWRS and its surrounding areas and investigate to what extent and why local policy makers decided not to follow up on some of the "sustainability ideas" that were mentioned during the interviews.

Author Contributions: X.L. is the key author, who conducted the case study, investigation, and formal analysis; ensured the methodology; and did most of the writing; D.S. contributed to the research design, structure, the key figure (visualization), and solidified the writing; M.d.B. conducted the overall cautious proofreading and revision; M.H. co-initiated the research project, reviewed and edited the manuscript; M.d.J. coordinated the whole research project and funding acquisition, and reviewed and validated the manuscript.

Funding: This research was funded by China Scholarship Council.

Acknowledgments: The authors thank China Scholarship Council (CSC) (No. 201606040174) and the Delft Initiative for Mobility and Infrastructures (DIMI) for financial support. The authors are also grateful for the inputs provided from the interviewees. The careful comments offered by the reviewers are quite acknowledged.

Conflicts of Interest: The authors declare no conflict of interest.

\section{References}

1. Molina-moreno, V.; Carlos, J.; Jorge, S. Proposal to Foster Sustainability through Circular Economy-Based Engineering: A Profitable Chain from Waste Management to Tunnel Lighting. Sustainability 2017, 9, 2229. [CrossRef]

2. The 12th Five Year Special Planning for the Development of Green Construction Technology. Available online: www.most.gov.cn/fggw/zfwj/zfwj2012/201206/W020120608553810621092.doc (accessed on 4 June 2019).

3. Nuñez-cacho, P.; Jaroslaw, G. What Gets Measured, Gets Done: Development of a Circular Economy Measurement Scale for Building Industry. Sustainability 2018, 10, 2340. [CrossRef]

4. Wu, X.; Zhao, W.; Yang, Z. Improving the Efficiency of Highway Construction Project Management Using Lean Management. Sustainability 2019, 11, 3646. [CrossRef]

5. Yang, W.; Qi, Z. Quantification of $\mathrm{CO}_{2}$ emissions of macro-infrastructure in China with simplified life cycle assessment. Nat. Hazards 2016, 82, 545-569. [CrossRef]

6. Standards Setters and Framework Providers to Support Better Reporting on the Sustainable Development Goals. Available online: https://www.globalreporting.org/information/news-and-press-center/Pages/betterreporting-SDGs.aspx (accessed on 18 June 2019).

7. Witjes, S.; Lozano, R. Towards a more Circular Economy: Proposing a framework linking sustainable public procurement and sustainable business models. Resour. Conserv. Recycl. 2016, 112, 37-44. [CrossRef]

8. Pla-julián, I. Is circular economy the key to transitioning towards sustainable development? Challenges from the perspective of care ethics. Futures 2019, 105, 67-77. [CrossRef]

9. Webb, R.; Bai, X.; Smith, M.S.; Costanza, R.; Griggs, D.; Moglia, M.; Neuman, M.; Newman, P.; Newton, P.; Norman, B.; et al. Sustainable urban systems: Co-design and framing for transformation. Ambio 2018, 47, 57-77. [CrossRef]

10. Turnheim, B.; Nykvist, B. Opening up the feasibility of sustainability transitions pathways (STPs): Representations, potentials, and conditions. Res. Policy 2019, 48, 775-788. [CrossRef]

11. Marsden, S. Assessment of transboundary environmental effects in the Pearl River Delta Region: Is there a role for strategic environmental assessment? Environ. Impact Assess. Rev. 2011, 31, 593-601. [CrossRef] 
12. Geng, Y.; Zhu, Q.; Doberstein, B.; Fujita, T. Implementing China's circular economy concept at the regional level: A review of progress in Dalian, China. Waste Manag. 2009, 29, 996-1002. [CrossRef]

13. Lee, Y.; Huang, C. Sustainability index for Taipei. Environ. Impact Assess. Rev. 2007, 27, 505-521. [CrossRef]

14. Guo, B.; Geng, Y.; Ren, J.; Zhu, L.; Liu, Y.; Sterr, T. Comparative assessment of circular economy development in China's four megacities: The case of Beijing, Chongqing, Shanghai and Urumqi. J. Clean. Prod. 2017, 162, 234-246. [CrossRef]

15. Cowan, D.M.; Dopart, P.; Ferracini, T.; Sahmel, J.; Merryman, K.; Gaffney, S.; Paustenbach, D.J. A cross-sectional analysis of reported corporate environmental sustainability practices. Regul. Toxicol. Pharmacol. 2010, 58, 524-538. [CrossRef]

16. Sauvé, S.; Bernard, S.; Sloan, P. Environmental sciences, sustainable development and circular economy: Alternative concepts for trans-disciplinary research. Environ. Dev. 2016, 17, 48-56. [CrossRef]

17. Liu, X.; Liu, G.; Yang, Z.; Chen, B.; Ulgiati, S. Comparing national environmental and economic performances through emergy sustainability indicators: Moving environmental ethics beyond anthropocentrism toward ecocentrism. Renew. Sustain. Energy Rev. 2016, 58, 1532-1542. [CrossRef]

18. Giddings, B.; Hopwood, B.; Brien, G.O.; Giddings, B.; Hopwood, B.; Brien, G.O. Environment, economy and society: Fitting them together into sustainable development. Sustain. Dev. 2002, 196, 187-196. [CrossRef]

19. Kazamia, E.; Smith, A.G. Assessing the environmental sustainability of biofuels. Trends Plant Sci. 2014, 19, 615-618. [CrossRef]

20. Ekins, P. Environmental sustainability: From environmental valuation to the sustainability gap. Prog. Phys. Geogr. Earth Environ. 2011, 35, 629-651. [CrossRef]

21. Environmental Functions. Available online: https://stats.oecd.org/glossary/detail.asp?ID=6424 (accessed on 6 June 2019).

22. Assefa, G.Ã.; Frostell, B. Social sustainability and social acceptance in technology assessment: A case study of energy technologies. Technol. Soc. 2007, 29, 63-78. [CrossRef]

23. Economic Sustainability. Available online: http://www.businessdictionary.com/definition/economicsustainability.html (accessed on 18 June 2019).

24. Social Sustainability. Available online: https://www.unglobalcompact.org/what-is-gc/our-work/social (accessed on 6 June 2019).

25. Borgonovi, E.; Compagni, A. Sustaining Universal Health Coverage: The Interaction of Social, Political, and Economic Sustainability. Value Health 2013, 16, S34-S38. [CrossRef]

26. Zhong, Y.; Wu, P. Economic sustainability, environmental sustainability and constructability indicators related to concrete- and steel-projects. J. Clean. Prod. 2015, 108, 748-756. [CrossRef]

27. Dubey, R.; Gunasekaran, A.; Childe, S.J.; Papadopoulos, T.; Luo, Z.; Fosso, S.; Roubaud, D. Can big data and predictive analytics improve social and environmental sustainability? Technol. Forecast. Soc. Chang. 2017, 144, 534-545. [CrossRef]

28. Glaser, M.; Diele, K. Asymmetric outcomes: Assessing central aspects of the biological, economic and social sustainability of a mangrove crab fishery, Ucides cordatus (Ocypodidae), in North Brazil. Ecol. Econ. 2004, 49, 361-373. [CrossRef]

29. Ahi, P.; Searcy, C. Assessing sustainability in the supply chain: A triple bottom line approach. Appl. Math. Model. 2015, 39, 2882-2896. [CrossRef]

30. Ugwu, O.O.; Haupt, T.C. Key performance indicators and assessment methods for infrastructure sustainability-A South African construction industry perspective. Build. Environ. 2007, 42, 665-680. [CrossRef]

31. Bradley, T.H.; Frank, A.A. Design, demonstrations and sustainability impact assessments for plug-in hybrid electric vehicles. Renew. Sustain. Energy Rev. 2009, 13, 115-128. [CrossRef]

32. Lindner, M.; Tommi, W.W.; Vo, D.; Valinger, E. Conducting sustainability impact assessments of forestry-wood chains: Examples of ToSIA applications. Eur. J. For. Res. 2012, 21-34. [CrossRef]

33. File: Sustainable development.svg. Available online: https://commons.wikimedia.org/wiki/File:Sustainable_ development.svg (accessed on 23 June 2019).

34. Basiago, A.D. Economic, social, and environmental sustainability in development theory and urban planning practice. Environmentalist 1999, 19, 145-161. [CrossRef]

35. Jackson, L.P.; Grinsted, A.; Jevrejeva, S. 21st Century Sea-Level Rise in Line with the Paris Accord Earth's Future. Earth's Future 2018, 6, 213-229. [CrossRef] 
36. The Sustainable Development Goals. Available online: https://ec.europa.eu/europeaid/policies/sustainabledevelopment-goals_en (accessed on 18 June 2019).

37. The National Sustainable Development Report of P. R. China. Available online: http://www.china-un.org/ chn/zgylhg/jsyfz/kccfz/P020120608811375491670.pdf (accessed on 6 June 2019).

38. Europe Moving towards a Sustainable Future. Available online: https://ec.europa.eu/info/sites/info/files/sdg multi-stakeholder_platform_input_to_reflection_paper_sustainable_europe2030.pdf (accessed on 6 June 2019).

39. Alessandro, S.D.; Luzzati, T.; Morroni, M. Energy transition towards economic and environmental sustainability: Feasible paths and policy implications. J. Clean. Prod. 2010, 18, 291-298. [CrossRef]

40. Kern, F.; Smith, A. Restructuring energy systems for sustainability? Energy transition policy in the Netherlands. Energy Policy 2008, 36, 4093-4103.

41. Child, M.; Koskinen, O.; Linnanen, L.; Breyer, C. Sustainability guardrails for energy scenarios of the global energy transition. Renew. Sustain. Energy Rev. 2018, 91, 321-334. [CrossRef]

42. Lock, I.; Seele, P.; Lock, I. Theorizing stakeholders of sustainability in the digital age. Sustain. Sci. 2017, 12, 235-245. [CrossRef]

43. Zhu, J. Efforts for a Circular Economy in China. A Comprehensive Review of Policies. J. Ind. Ecol. 2018, 23, 110-118. [CrossRef]

44. Geissdoerfer, M.; Savaget, P.; Bocken, N.M.P.; Hultink, E.J. The Circular Economy-A new sustainability paradigm? J. Clean. Prod. 2017, 143, 757-768. [CrossRef]

45. Schroeder, P. The Relevance of Circular Economy Practices to the Sustainable Development Goals. J. Ind. Ecol. 2018, 23, 77-95. [CrossRef]

46. Morrissey, J.; Iyer-raniga, U.; Mclaughlin, P.; Mills, A. A Strategic Project Appraisal framework for ecologically sustainable urban infrastructure. Environ. Impact Assess. Rev. 2012, 33, 55-65. [CrossRef]

47. Shen, L.; Asce, M.; Wu, Y.; Zhang, X.; Ph, D. Key Assessment Indicators for the Sustainability of Infrastructure Projects. J. Constr. Eng. Manag. 2011, 137, 441-451. [CrossRef]

48. Ugwu, O.O.; Kumaraswamy, M.M.; Wong, A.; Ng, S.T. Sustainability appraisal in infrastructure projects (SUSAIP) Part 1. Development of indicators and computational methods. Autom. Constr. 2006, 15, $239-251$. [CrossRef]

49. Ugwu, O.O.; Kumaraswamy, M.M.; Wong, A.; Ng, S.T. Sustainability appraisal in infrastructure projects (SUSAIP): Part 2: A case study in bridge design. Autom. Constr. 2006, 15, 229-238. [CrossRef]

50. Koo, D.; Ariaratnam, S.T.; Jr, E.K. Development of a sustainability assessment model for underground infrastructure projects. Can. J. Civ. Eng. 2009, 776, 765-776. [CrossRef]

51. Zavrl, M.S.; Zeren, M.T. Sustainability of Urban Infrastructures. Sustainability 2010, 2, 2950. [CrossRef]

52. Fernández-sánchez, G.; Rodríguez-lópez, F. A methodology to identify sustainability indicators in construction project management-Application to infrastructure projects in Spain. Ecol. Indic. 2010, 10, 1193-1201. [CrossRef]

53. Elbarkouky, M.M.G.; Cairo, N. A Multi-Criteria Prioritization Framework (MCPF) to Assess Infrastructure Sustainability Objectives and Prioritize Damaged Infrastructure Assets in Developing Countries. J. Sustain. Dev. 2012, 5, 1-13. [CrossRef]

54. Karaca, F.; Graham, P.; Machell, J.; Camci, F. A comparative analysis framework for assessing the sustainability of a combined water and energy infrastructure. Technol. Forecast. Soc. Chang. 2015, 90, 456-468. [CrossRef]

55. Amasuomo, E.; Hasnain, S.A.; Osanyinlusi, A.Y. Sustainable Development in the Context of Major Infrastructure Projects in United Kingdom. J. Geosci. Environ. Prot. 2015, 3, 44-55. [CrossRef]

56. Bueno, P.C.; Vassallo, J.M.; Cheung, K. Sustainability Assessment of Transport Infrastructure Projects: A Review of Existing Tools and Methods. Transp. Rev. 2017, 35, 1-28. [CrossRef]

57. Reza, B.; Sadiq, R.; Hewage, K. Emergy-based life cycle assessment (Em-LCA) for sustainability appraisal of infrastructure systems: A case study on paved roads. Clean Technol. Environ. Policy 2014, 16, 251-266. [CrossRef]

58. Tsai, C.Y.; Chang, A.S. Framework for developing construction sustainability items: The example of highway design. J. Clean. Prod. 2012, 20, 127-136. [CrossRef]

59. Goh, K.C.; Yang, J. Importance of Sustainability-Related Cost Components in Highway Infrastructure: Perspective of Stakeholders in Australia. J. Infrastruct. Syst. 2014, 20, 1-9. [CrossRef]

60. Mostafa, M.A.; El-gohary, N.M.; Asce, A.M. Stakeholder-Sensitive Social Welfare-Oriented Benefit Analysis for Sustainable Infrastructure Project Development. J. Constr. Eng. Manag. 2014, 140, 1-12. [CrossRef] 
61. Yicai. Available online: https://www.yicai.com/news/5293378.html (accessed on 4 June 2019).

62. Development and Reform Commission of Jingmen. Available online: http://www.jmfgw.gov.cn/ywgz/xhjj/ news/1397.html (accessed on 6 June 2019).

63. Hospital, H.C.; Lauderdale, F.; Policy, N.; Affairs, U.; International, F.; Affairs, P. Content Analysis: Review of Methods and Their Applications. J. Nutr. Educ. Behav. 2002, 34, 224-230.

64. Elo, S.; Kääriäinen, M.; Kanste, O.; Pölkki, T. Qualitative Content Analysis: A Focus on Trustworthiness. SAGE Open 2014, 4, 1-10. [CrossRef]

65. Exploratory Social Network Analysis with Pajek. Available online: courses.arch.ntua.gr/fsr\%2F144992/PajekManual.pdf (accessed on 21 June 2019).

66. Zhang, K.; Wen, Z. Review and challenges of policies of environmental protection and sustainable development in China. J. Environ. Manag. 2008, 88, 1249-1261. [CrossRef]

67. Zeng, H.; Chen, X.; Xiao, X.; Zhou, Z. Institutional pressures, sustainable supply chain management, and circular economy capability: Empirical evidence from Chinese eco-industrial park firms. J. Clean. Prod. 2017, 155, 54-65. [CrossRef]

68. The Promotion Law of People's Republic of China (full). Available online: http://www.china.com.cn/policy/ txt/2008-08/30/content_16359917.htm (accessed on 19 June 2019).

69. Notice from the State Council about the Release of 13th Five Year Eco-Environment Protection Planning. Available online: http://www.gov.cn/zhengce/content/2016-12/05/content_5143290.htm (accessed on 23 June 2019).

70. The Proposal of Promoting the Comprehensive and Deep Development of Green Transport from Ministry of Transport. Available online: zizhan.mot.gov.cn/zfxxgk/bnssj/zcyjs/201712/t20171206_2945768.html (accessed on 23 June 2019).

71. Opinions from the Hubei Provincial Government about the Acceleration of CE. Available online: http://www.mofcom.gov.cn/aarticle/b/g/200606/20060602521141.html (accessed on 23 June 2019).

72. Notice from Hubei Provincial Government about the Releasing of the 13th Five Year Plan in 2016 for Hubei on a Comprehensive Transportation System. Available online: http://www.hubei.gov.cn/govfile/ezf/201609/ t20160908_1032861.shtml (accessed on 23 June 2019).

73. Dieppe, A.; Gilhooly, R.; Han, J. The Transition of China to Sustainable Growth-Implications for the Global Economy and the Euro Area; European Central Bank (ECB): Frankfurt am Main, Germany, 2018. Available online: https://ssrn.com/abstract=3113109 (accessed on 23 June 2019).

74. Ghisellini, P.; Cialani, C.; Ulgiati, S. A review on circular economy: The expected transition to a balanced interplay of environmental and economic systems. J. Clean. Prod. 2016, 114, 11-32. [CrossRef]

75. Balanay, R.; Halog, A. Charting Policy Directions for Mining's Sustainability with Circular Economy. Recycling 2016, 1, 219. [CrossRef]

76. Shin, M.H.; Lee, H.K.; Kim, H.Y. Benefit-Cost Analysis of Building Information Modeling (BIM) in a Railway Site. Sustainability 2018, 10, 4303. [CrossRef]

77. Hertogh, M.J.C.M. Opportunity framing. In Management of Engineering Projects-People Are Key; Bakker, H.L.M., de Kleijn, J.P., Eds.; NAP: Nijkerk, The Netherlands, 2014; p. 102, ISBN 9789081216203.

(C) 2019 by the authors. Licensee MDPI, Basel, Switzerland. This article is an open access article distributed under the terms and conditions of the Creative Commons Attribution (CC BY) license (http://creativecommons.org/licenses/by/4.0/). 